\title{
NEW APPROACHES IN THE CONSUMER - SUPPLIER RELATIONSHIP REGARDING MALFUNCTIONS IN THE ELECTROENERGETIC SYSTEMS AND FROM THE PERSPECTIVE OF THE IOT DEVELOPMENT
}

\author{
B. BOTEA ${ }^{1}$, I. MARINESCU ${ }^{1}$ \\ ${ }^{1}$ PHD STUDENT, VALAHIA UNIVERSITY OF TÂRGOVIȘTE \\ E-mail: bvbotea@gmail.com, ioan.marinescu@yahoo.com
}

\begin{abstract}
The article emphasizes certain specific issues that a small and medium enterprise can encounter in terms of deviation from the rules regulating the quality of electrical power, as well as a couple suggestions for their regulation.
\end{abstract}

Keywords: standardization, quality of electricity, IoT development

\section{INTRODUCTION}

Quality, as defined by the International Organization for Standardization, is "the totality of the features and particularities of a product or service that characterizes the ability to respond to potential or expressed needs of the user."

The quality of electricity can be defined in many ways, which is why it was necessary to define clearly and concisely the notion of the quality of electricity and to standardize the parameters that are involved in defining this notion.

In this respect, it can be said about the quality of electricity that refers to the quality of the voltage and the quality of the current, and any deviation of the current or voltage from the ideal values is a quality irregularity of the electric power [1].

The Council of European Energy Regulators uses the expression of service quality in the supply of electricity, which refers to three aspects [2]:

- Voltage quality, describing transients, frequency, amplitude and harmonics;

- Commercial quality, describing the relationship between the supplier and the consumer;

- Continuity of delivery, describing long and short interruptions.

The present article studies the quality of electrical energy parameters from the consumer-supplier relationship.

There are two case studies that highlight two types of defects of the JT power supply system of an industrial consumer in Prahova County Romania. The two defects that took place over a period of 8 months have caused significant financial damage to the consumer, which is analysed and detailed.
Considering the frequency of occurrence of these defects in the electrical system and the significant damages caused to the consumers are proposed both technical solutions for continuous monitoring of the electric power parameters and improvement of the current legal framework or establishing the contractual relationship between the supplier and consumer.

\section{DEFECTS IN POWER SYSTEMS AND DEVELOPMENT OF IOT}

Electricity consumers are divided, according to the criteria of importance and the need to ensure continuity in electricity supply, into the following categories of importance [3]:

- Consumers of the special category of importance it is a category in which consumers are of major importance because any interruption in power supply can cause explosions, fires, equipment destruction, human casualties, etc. This would be the case, for example, for the main fan stations, water discharge pumps and personnel extraction facilities;

- Consumers of the first category of importance where the interruption in power supply causes the disruption of continuous-process technology processes as well as a decrease in production volume, a volume that cannot be recovered when the power supply is restored. This category encompasses all power receivers that serve the technological fluxes that are being carried out continuously;

- Consumers of the second category of importance where any interruption in the power supply has the effect of not achieving the volume of production, but which can be restored after the restoration of the electricity supply. Here are the receivers that serve the industrial enterprises;

- Consumers of the third category of importance which include consumers of minor importance whose interruption in the supply of electricity do not have an immediate effect on the production process. These are, for example, surface lighting consumers as well as machine tools serving the auxiliary processes of industrial enterprises.

Labor protection rules provide for ' 0 ' category consumers to have a backup source [4]. Also in the case of a power shortage in the power supply systems, in the beginning there will be disconnected from the network - in this order 
- those of the third, second, and first category consumers and only in the extreme case those of the category zero.

In this respect, the supply systems for consumers should be designed to ensure the quality of the power supply needed to carry out their normal activity under the conditions of accepted damages that may result from any interruptions in power supply.

All improved power supply schemes are based on the existence of a backup or backup source that provides the necessary power during the main power supply interruption.

The type of power scheme and its characteristics is determined by the form in which the backup energy is stored. The most common solutions are based on energy stored in the form of fuel (intervention groups), chemical energy (energy accumulators), kinetic energy (fly wheel).

However, generating a back-up power from the public network, although it offers the possibility of taking all the necessary power without restrictions on the absorbed power, and the availability of the source is virtually immediate (after a very short time) is at the same time one of the most expensive [3].

This scheme is widely used for consumers with ongoing processes that require relatively high power. Providing power from two different independent nodes of the public electric grid often assures a power supply with safety parameters that meet the requirements of consumers.

\subsection{The main types of defects in the electrical system}

The main defects of the power system that fall, from the point of view of the IEC, are short-term variations in voltage and / or short-term interruption [5], [6].

Short voltage variations are caused by fault situations, in most cases by failures, by the connection of large consumers to the mains, which absorb very high starting currents or the temporary lack of electrical continuity in power supply networks.

Irrespective of the type of defect, its influence on the voltage consists in the appearance of a short-lived variation in its size until the protective devices act to suppress the causes and the effects of the damage.

Power failure is the situation where the supply voltage drops to less than 0.1 pu (i.e. $10 \%$ of the declared Uc voltage) for a period of time not exceeding 1 minute. It is noted that according to IEC 60038: 2002 [5] standard, two different voltages across the network and in consumer electrical installations are defined:

- the supply voltage, which is the phase-to-neutral or neutral voltage in the CCP, i.e. the main power supply of the installation, which is also the point of delimitation between the supplier's network and the consumer's installation;

- the usage voltage, which is the voltage between phaseto-line, or phase-neutral-phase, at the terminals of the receivers.

The duration of the interruption depends generally on the ability to reconnect protective equipment. Instant Reconnection will limit interruption caused by a nonpermanent fault to less than 30 periods $(0.6 \mathrm{~s})$. The timed reconnection of the protection device can generate a momentary interruption of $10 \mathrm{~ms}-3 \mathrm{~s}$ or a temporary delay of $3 \mathrm{~s}-1 \mathrm{~min}$.

It is worth noting that the instantaneous voltage value does not decrease to zero as soon as the system failure resulting from the power failure has occurred. This residual voltage has as its main cause the electromotive voltages induced by the engines at that moment on the broken line.

Voltage dips - IEC 60050 [6] defines the voltage gap as the untimely voltage drop at a point in an electrical power supply system followed by restoring its value after a short period of time between several periods and a few seconds.

A more concise definition is given in the IEEE 1159-1995 [7] standard, according to which voltage gaps represent decreases between $0.1 \mathrm{pu}$ and 0.9 pu of the effective value of the voltage - with the preservation of the frequency value, for a short period of time having a duration of between 0.5 periods $-10 \mathrm{~ms}$ and one minute, followed by resuming the voltage after this time. This definition was taken $100 \%$ by the standard SR EN 50160 [8].

Overloadings are defined as increases in the effective voltage or current value (with frequency retention) for a period of half-period $(0.01 \mathrm{~s})$ and one minute [9]. Their typical amplitudes are between $1.1 \mathrm{pu}$ and $1.8 \mathrm{pu}$ of the actual value of the respective size. The amplitude of the overvoltages is also described by the residual value of the magnitude, which in this case is always supraunitary.

Over-stresses may occur due to a grounding failure of a supply line, which leads to a temporary lift of the voltage on the remaining lines. These may also occur when disconnecting from the mains a significant load or by coupling a high capacity capacitance capacitor battery. The dimensions that characterize overvoltages are amplitude and duration. The gravity of a surge occurring as a direct link to a single-phase short-circuit depends on where the fault occurred, the system impedance and the earth connection.

Therefore, in a non-earth-connected system, in the case of a single-phase short-circuit, the stresses between the line and the earth corresponding to the non-fused phases will be $\sqrt{3 p u}$.

In a grounded system near the transformation station, due to the usual triangle-star connection of the transformer, which offers a low homopolar impedance path for the 
fault current, there will be no increase in the voltage value.

\subsection{Internet-of-things (IoT)}

The Internet-of-things (IoT) era opens to new technological methods and scenarios, for the development of work processes and applications [10].

In a world where physical objects are scattered in the environment and could be the source of information used to identify events of interest, the basic idea IoT is to equip them with a minimal computational power, to make them able to interconnect and cooperate with their neighbours, in order to achieve common goals [11].

Since objects are no longer passive entity, but can be programmed to perform operations autonomously, they are called smart objects (SO). The SOs integrate specific sensing part and are reachable (contactable) through the network using a unique address and the TCP/IP protocol. Some research activities are devoted to develop useful technology to enable sensors embedded in SO to perform different kind of measurements, and to use the Internet connection for the remote monitoring [12]. The global market success of SO, such as the smart sensors, smart meter [13], [14] derives from low cost, small size, and the possibility to monitor multiple parameters at the same time. Such devices allow home-automation applications, power management [15], power grid functioning, surveillance and many other innovative applications [16]. This leads to predict that the number of the devices interconnected will grow exponentially. See image below (Figure 1).

Nowadays even in the industrial field a modernization and an automation process of the equipment is carried out, using network communication protocols. In particular, the term Industry 4.0 [13] refers to an innovative approach used to connect through Internet all the devices, so that they can work in a more efficient, collaborative and resilient way.

In this scenario, two are the challenges that are becoming increasingly important:

- high quantity of produced data, known as Big Data, that need fast processing, depending on the application type;

- manager of concurrent measurements and the suitable actions with the use of heterogeneous sensors, actuators and communication protocols.

IoT and Industry 4.0 can be considered as an application and an extension of Distributed Measurement Systems (DMSs) technology. A DMS is a heterogeneous set of measurement instruments (MI) equipping the nodes connected one another through the network, that communicate using message-passing techniques.

The aim of this paper is to provide a first contribution to move towards a unified approach for the DMSs geared to home automation, through the proposal of some useful guidelines for the design and the implementation of an application development tool.

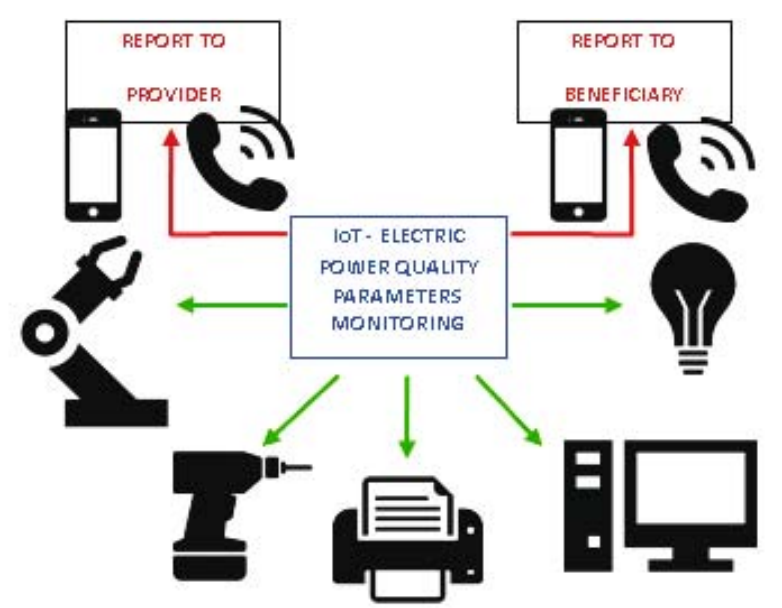

Figure 1. IoT and the electroenergetic system.

\section{THE SUPPLIER - CONSUMMER RELATION: CASE STUDY}

Following documentation at one of the most important producers of electrical components in Prahova County, Romania, namely T.C. Measurement and Control S.R.L. based in Câmpina Municipality, which produces thermocouples, electric cables with special destinations, electric sensors, including those for the aviation industry, there were two types of defects that will be presented below.

\subsection{Power outage}

During January, there were disruptions in the power supply due to the excessive use of electric heating sources which had the effect of overloading the electrical grid and which ultimately resulted in damages resulting in shortterm interruptions in the supply of energy electric.

The cost of economic losses due to short-term interruptions would be at least 1000 Euros at the sensor production unit and 6000 Euros at the special cable production unit.

At the sensor production unit, due to the endowment of the production unit with numerical cutting machines, the amount of EUR 1,000 can be even higher if the robotic tools left without power destroy the attached tools, considering a tool for them has a starting price of several dozen euro and can climb up to several hundred.

\subsection{Overloads}

During July, there was a power failure that showed the characteristics of af a power overload.

The cost of economic losses due to overvoltage would be around 10000 Euros at the sensor production unit that included the cost of the two defective Servers and the UPS 
plus the production delays caused by shutting down the numerical cutting machines for several hours till the IT and intervention team succeeded in restarting a server and rebuilding it after backing up the other server.

In the graph of Figure 2 are figured the economic losses incurred and the production costs of the company in January and April 2017. As you can see the production costs increase proportionally with the value of the damages recorded.

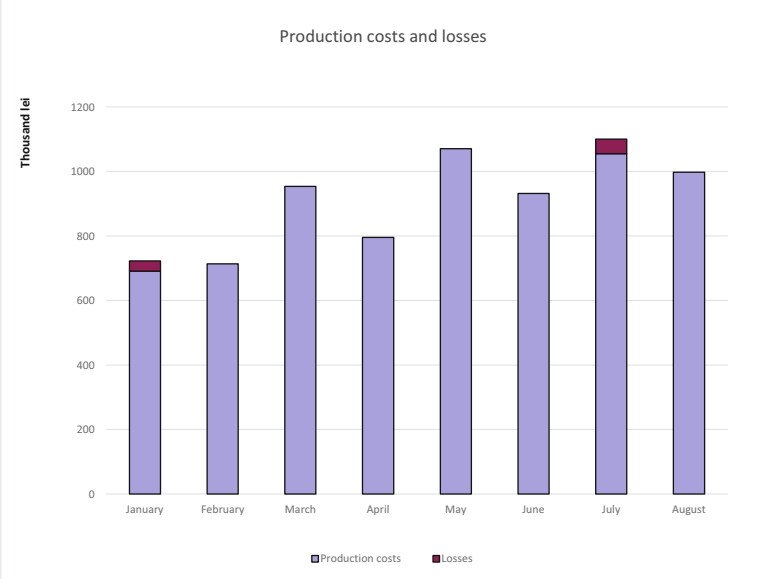

Figure 2. Production costs and losses due to defects in the power system

In January the losses were $4.55 \%$ and in July the losses were around $4.26 \%$; in a market economy based on fierce competition in the field, these values can be up to almost the whole profit net in a month of lucrative activity.

\subsection{A new approach regarding the relation between supplier and consumer}

Households are entitled to receive compensation when their appliances are damaged due to accidental overvoltages, it is specified in the Electricity Supply Regulation, approved by ANRE Order no. 64/2014 [17]. In this respect, the conditions for the award of damages have also recently been established.

These are presented in the ANRE Order no. 177/2015 for the approval of the procedure for the granting of compensations to household customers for domestic appliances damaged as a result of accidental overvoltages caused by the fault of the network operator, which appeared in the Official Gazette, Part I, no. 971 of 29 December 2015 and shall apply from the date of publication [18].

"This procedure sets out how to deal with claims for damages in the case of damage to home receivers as a result of accidental overvoltages caused by the fault of the network operator, the conditions for granting and the method of calculating the compensation awarded," the document states.

Compensation is made in cash for any consumer goods for domestic use with electricity (at $230 \mathrm{~V} / 400 \mathrm{~V}$ voltages). The only cases where compensation is not provided are for electric lamps and electrothermal receivers that do not contain electronic components.

Compensation is granted by the network operator directly to the household customers or through the electricity supplier, as the case may be, according to ANRE Order no. 177/2015. This is only possible if the network operator, following his own investigation, finds his damages and guilt for producing them.

In my opinion, leaving the investigation at the hands of the operator can lead to abuse and delay in granting compensation. Therefore, as a consequence, it requires a change in the current legislation by creating an independent body to the National Authority for Consumer Protection to be invested with mediation attribute and decision in granting compensation.

In case of household appliances failure due to accidental overvoltages, household customers must file a claim for compensation with the electricity supplier or the network operator, as the case may be.

If, following their investigation, the request proves to be well founded, the following supporting documents are also required:

- Purchase documents (receipt, invoice, tax receipt etc.) or a declaration on your own responsibility regarding the date of purchase of the appliance;

- Documents relating to the repair of damaged appliances (receipt, invoice, fiscal receipt) or, if repair is not possible, confirmation of this by a company specialized in the repair of household appliances.

Under the already applicable procedure, damages are granted only if a number of conditions are fulfilled cumulatively as follows:

- the place of consumption where the overvoltage occurred is supplied with electricity on the basis of a contract for the supply of electricity / network contract;

- accidental overvoltages were not based on atmospheric origin;

- failed appliances are homologated and supplied with electricity through properly dimensioned circuits, technically appropriate;

- failure of the appliance has occurred due to accidental overvoltages in the grid operator's network due to it;

- the household customer has in writing requested the provider or the network operator (as the case may be) to pay the compensation within the legal time limit.

Compensation can only be granted if there is a written request from the customer whenever he suffers from accidental overvoltages.

Steps to get compensation:

In order to claim compensation, household customers have a maximum of ten business days from the date of accidental overheating that has affected the electrical equipment. The written request must be addressed to the provider or network operator on a case-by-case basis. 
Customers may also submit the request after this period has been exceeded, at the time they see the damage to the appliance, but in this case, the claim for compensation will have to be accompanied by documents to motivate the delay.

Upon receipt of the request by the network operator, within ten working days, the customer will agree with the customers, will set the date for the verification of the notifications at home. After verification, ascertained, household customers are notified of whether or not to grant compensation.

If the claim is justified, the household customers have sixty days from the notice to submit the supporting documents required for the compensation. In the end, the supplier or network operator pays the damages in accordance with the contractual provisions between the parties.

If there are disagreements between the customer, the supplier and the network operator following the investigation - regarding the operator's fault and / or the value of the compensation - the parties may address the courts, but as stated above, it is necessary to create an independent body that can protect the consumer of possible abuses of the supplier such as unreasonable use of the courts in order to limit or delay compensation.

In the case of non-household consumers, compensation as well as the terms of the grant are included in the electricity supply contract.

It is required for ANRE to intervene by drafting an order similar to ANRE Order no. 177/2015 for the approval of the procedure for the granting of compensations to household customers for domestic appliances damaged as a result of accidental overvoltages caused by the fault of the network operator, which appeared in the Official Gazette, Part I, no. 971 of December 29, 2015 to regulate the non-domestic consumer sector [19].

It would also be in the interest of both parties to install measuring devices in the IO sphere, possibly embedded in the electricity meter, to monitor the quality of electricity in the air and to announce through mobile applications both the decision-makers on both sides, respectively the supplier - consumer, about deviations from energy quality.

And in this situation, ANRE should come to the customers through a regulation so that they no longer depend on the supplier for the detection of the causes that caused the damage related to the supply of electric power.

On the other hand, we believe that the supplier is equally interested in demonstrating that the service delivered is of good quality and is not to blame for possible damage to the consumer's network.

\section{CONCLUSIONS}

In the respect of the above, we consider that A.N.R.E. should draft an order similar to ANRE Order no. 177/2015 for the approval of the procedure for the granting of compensations to household customers for domestic appliances damaged as a result of accidental overvoltages caused by the fault of the network operator, which appeared in the Official Gazette, Part I, no. 971 of 29 December 2015 and to regulate also the non-household consumers sector.

It would also be in the interest of both parties to install measuring devices in the IO sphere, possibly embedded in the electricity meter, to monitor the quality of electricity in the air and to announce through mobile applications both the decision-makers on both sides, respectively the supplier - consumer, about deviations from energy quality.

In this situation, ANRE should come to the customers through a regulation so that they will no longer depend on the supplier for the detection of the causes that have caused the damage to the power supply and through which to establish the technical characteristics of a IoT and the way it can be installed, as well as who is responsible for the acquisition, assembly, etc. costs.

On the other hand, we consider that the supplier is interested in the same measure as the consumer to prove that the service delivered is of good quality and is not him to blame for possible damage to the consumer's network.

\section{REFERENCES}

[1] H. Albert, N. Golovanov, C. Golovanov, L. Elefterescu, „Nowadays Problems Regarding Quality Monitoring of Electric Power (Probleme actuale privind monitorizarea calității energiei electrice)", CEEE 2003

[2] C. Gherasim, T. Croes, J. Driesen, R. Belmans, „Amplitude, Phase and frecquency Estimation based on Analytical Representation of Power System Signals", Proceedings of the International Conference on Power System Transients, June 1923 Montreal, canada, 2005

[3] Albert H., Florea I., Iordanescu I., , Industrial Enterprises Power Supply (Alimentarea cu energie electrica a intreprinderilor industriale)", Editura Tehnica, Bucuresti, 1978

[4] "Normative for the Design and Execution of Electrical Installations at the Consumer with Voltages up to $1000 \mathrm{~V} \mathrm{ca}$. and $1500 \mathrm{~V}$, Direct Current (Normativ pentru proiectarea şi executarea instalatiilor electrice la consumator cu tensiuni până la $1000 \mathrm{~V}$ c.a. şi $1500 \mathrm{~V}$ in cc), I-7.

[5] IEC 60050 (IEV), International Electrotechnical Vocabulary (IEV) - Chapter: Electromagnetic Compatibility

[6] Chapman, D., "Power Quality Application Guide, 
Voltage Dips - Introduction", Copper Development Association, March 2001, http://www.cda.org.uk/megab2/elecapps/PQ Guid e/51- voltage-dips.pdf

[7] SR EN 61000-6-2:2003 "Electromagnetic Compatibility - Generic Standards. Immunity for Industrial Environments (Compatibilitate electromagnetică (CEM). Partea 6-2: Standarde generice. Imunitate pentru mediile industriale)"

[8] SR EN 61000-6-1:2003 "Electromagnetic Compatibility - Generic Standards. Immunity in residential, commercial and light industrial areas. (Compatibilitate electromagnetică (CEM). Partea 6-1: Standarde generice. Imunitatea în mediile rezidenţiale, comerciale şi uşor industrializate)"

[9] SR EN 61000-6-4:2003 "Electromagnetic Compatibility - Generic Standards. Emission Standard for Industrial Environment (Compatibilitate electromagnetică (CEM). Partea 6-4: Standarde generice. Standard de emisie pentru mediile industriale)",

[10] E. Spanò, S. Di Pascoli, G. Iannaccone, "Internet-of things infrastructure as a platform for distributed measurement applications", Instrumentation and Measurement Technology Conference (I2MTC), 2015 IEEE International. IEEE, 2015.

[11] X. Feng, L. T. Yang, L. Wang, A. Vinel, "Internet of things" International Journal of Communication Systems 25.9, 2012

[12] F. Lamonaca, K. Barbè, G. Polimeni, D. Grimaldi, "Health parameters monitoring by smartphone for quality of life improvement Measurement", Measurement, Volume 73, Issue 28, 2015

[13] J. Lee, B. Bagheri, H. Kao. "A cyber-physical systems architecture for industry 4.0-based manufacturing systems" Manufacturing Letters 3, 2015

[14] A. Botta, W. De Donato, V. Persico, A. Pescapé, "Integration of cloud computing and internet of things: a survey" Future Generation Computer Systems 56, 2016

[15] D.L. Carnì, D. Grimaldi, F. Lamonaca, L. Martirano, G. Parise " A Smart Control to Operate the Lighting System in the Road Tunnels", Proc. Of IDAACS 2013- IEEE International Conference on Intelligent Data Acquisition and Advanced Computing Systems: Technology and Applications, 12-14, 2013

[16] M. Di Manno, P. Varilone, P. Verde, M. De Santis, C. Di Perna, M. Salemme, "User friendly smart distributed measurement system for monitoring and assessing the electrical power quality" AEIT International Annual Conference (AEIT), 2015

[17] ANRE Order no. 64/2014 regarding the approval of the Electricity Regulation Regulation (Ordinul ANRE nr. 64/2014 pentru aprobarea Regulamentul de furnizare a energiei electrice, publicat în Monitorul Oficial, Partea I, nr. 544 din 23 iulie 2014)

[18] ANRE Order no. 177/2015 approving the Procedure for the granting of households' indemnities for domestic appliances damaged as a result of accidental overvoltages caused by the fault of the network operator (Ordinul ANRE $n r$. 177/2015 pentru aprobarea Procedurii privind acordarea despăgubirilor clienţilor casnici pentru receptoarele electrocasnice deteriorate ca efect al unor supratensiuni accidentale produse din culpa operatorului de rețea, publicat în Monitorul Oficial, Partea I, nr. 971 din 29 decembrie 2015).

[19] National Regulatory Authority for Energy, National Report 2016 (Autoritatea Naţională de Reglementare în Domeniul Energiei, Raport Național 2016). 